\title{
BMJ Open Longitudinal study of social participation and well-being among persons with spinal cord injury and their partners (pro-WELL)
}

\author{
Christine Fekete, ${ }^{1}$ Martin W G Brinkhof, ${ }^{1,2}$ Hannah Tough, ${ }^{1,2}$ Johannes Siegrist ${ }^{3}$
}

To cite: Fekete $C$, Brinkhof MWG, Tough $\mathrm{H}$, et al. Longitudinal study of social participation and wellbeing among persons with spinal cord injury and their partners (pro-WELL). BMJ Open 2017;7:e011597. doi:10.1136/bmjopen-2016011597

- Prepublication history for this paper is available online. To view these files please visit the journal online (http://dx.doi.org/10.1136/ bmjopen-2016-011597).

Received 22 February 2016 Revised 13 October 2016 Accepted 20 October 2016

CrossMark

\begin{abstract}
${ }^{1}$ Swiss Paraplegic Research, Nottwil, Switzerland ${ }^{2}$ Department of Health Sciences and Health Policy, University of Lucerne, Lucerne, Switzerland

${ }^{3}$ Faculty of Medicine, Senior Professorship 'Work Stress Research', University of Duesseldorf, Life-ScienceCenter, Duesseldorf, Germany
\end{abstract}

Correspondence to Dr Christine Fekete; christine.fekete@paraplegie.ch

\section{ABSTRACT}

Purpose: Social participation is an important determinant of well-being. Among persons with disabilities, and with spinal cord injury (SCI) in particular, opportunities for social participation are restricted and may impact well-being. The longitudinal pro-WELL study aims to investigate associations of 2 major domains of social participation with well-being: (1) availability and quality of close social relationships and (2) acting in core social roles (eg, paid work). The joint inclusion of persons with $\mathrm{SCl}$ and their partners is a major innovative aspect of this study enabling an in-depth analysis of interpersonal dynamics in coping with disability.

Participants: Pro-WELL is a nested project of the Swiss Spinal Cord Injury Cohort Study (SwiSCl) and involves community-dwelling persons aged 30-65 with $\mathrm{SCl}$ and their partners living in Switzerland. Baseline data were collected from mid-2015 to early 2016 by telephone interviews and questionnaires. The first and second follow-up assessments are scheduled with a 6 months interval.

Findings to date: The baseline sample consists of 133 persons with $\mathrm{SCl}$ and their partners. We provide an overview of baseline characteristics and well-being and describe recruitment outcomes and participation rates. A comprehensive non-response analysis demonstrates adequate representation of the source population with negligible selection bias regarding sociodemographic and lesion characteristics.

Future plans: The prospective data collection and analysis of month 6 and 12 assessments are ongoing and tests of the main research hypotheses will be performed. Findings will be disseminated through peer-reviewed journals and scientific conferences. A workshop and a newsletter on study findings are proposed to feed back findings to participants and other stakeholders.

\section{INTRODUCTION}

The burden of disability in modern societies provides a major challenge to health and social policies. ${ }^{1}$ Although disability is commonly most prevalent in the aged
Strengths and limitations of this study

- The theory-grounded prospective pro-WELL study analyses associations of social participation with well-being in disability.

- The inclusion of persons with spinal cord injury and their partners enables an in-depth analysis of interpersonal dynamics in coping with disability.

- According to international guidelines, recruitment outcomes, participation rates and a nonresponse analysis are provided, demonstrating adequate representation of the source population by the pro-WELL sample.

- Small sample size and low response rate need to be considered in the interpretation of findings.

population, it can occur at any stage of the life course, as in the case of spinal cord injury (SCI). An SCI is caused by traumatic or non-traumatic damage to the spinal cord, a soft tissue that is made up of nerve tracts and constitutes the extended portion of the central nervous system that links the brain to the muscles of the body and most sensory nerves to the brain. ${ }^{2}$ Depending on the level and the completeness of the damage or injury, SCI is classified as tetraplegia (upper section of the spine) or paraplegia (lower section of the spine), complete injury in case of a total loss of sensation and movement, or incomplete injury in case sensation or movement is only partially lost. ${ }^{2}{ }^{3}$ Consequently, SCI may have serious consequences on functioning and health of affected individuals and oftentimes leads to major disability. ${ }^{2} 3$

The occurrence of an SCI leads to substantial costs and restrictions in social participation, for example, limited access to employment opportunities, ${ }^{2-5}$ or barriers in maintaining or establishing social relationships. These constraints add to the burden of managing disability in persons with SCI and 
their partners, often resulting in reduced well-being. ${ }^{6} 7$ The study of well-being among persons with SCI is the subject of a rich literature. ${ }^{8} 9$ Several studies analysed the impact of people's everyday life circumstances on their well-being, that is, their social participation in terms of close social relationships ${ }^{10}{ }^{11}$ and involvement in core social roles such as paid or unpaid work. ${ }^{5}$ 12-14 However, most studies failed to specify the supposed underlying theoretical link. Here, we set out to test these associations by introducing the notion of social productivity, and its function in meeting distinct human needs. ${ }^{15}$ Following a short description of this theoretical background, this cohort profile outlines the methodology (design, sampling, recruitment procedures and measurements), the recruitment outcomes (participation rates and basic characteristics of baseline participants) and the non-response analysis of the pro-WELL study. Further, strengths and limitations are briefly discussed.

\section{Theoretical background}

Social participation is fundamental for the fulfilment of human needs. Human needs include a desire for social affiliation, ${ }^{16}$ a motivation to develop and maintain one's skills and competences through goal-directed activities, ${ }^{17} 18$ and a striving for recognition and appreciation from significant others. ${ }^{19} 20$ The fulfilment of these needs provide experiences of belonging and social support, personal control, social reward and selfesteem. ${ }^{16-21}$ However, whether these needs are met or not largely depends on the opportunities for close social relationships ${ }^{22}$ and for acting in core social roles. ${ }^{23}$ By acting in core social roles, such as paid work, housework or caregiving, persons are socially productive. $^{24}$ Involvement in socially productive activities and close social relationships may facilitate the fulfilment of related needs of belonging, personal control and social recognition which in turn strengthen well-being. ${ }^{17} 25$ Conversely, if these needs remain unmet, social exclusion, ${ }^{22}$ powerlessness ${ }^{26}$ and social reward deficiency ${ }^{27}$ are likely consequences. We therefore maintain that the availability and the quality of close social relationships and productive activities are critical determinants of well-being.

The Convention on the Rights of Persons with Disabilities (CRPD) recognises the critical importance of social participation, ${ }^{28}$ yet many persons living with disabilities still experience substantial barriers regarding participation. ${ }^{135}$ Given the chronic nature of SCI, participation limitations are lifelong and may affect the development and preservation of close social relationships and the involvement in productive activities. ${ }^{3} 5$ Accordingly, people with disabilities are at risk of experiencing poorer well-being than able-bodied persons. ${ }^{1} 382930$ The pro-WELL study aims to investigate the association of availability and quality of close social relationships and socially productive activities with well-being in persons with SCI and their partners. We test the hypothesis that the quality of social relationships and socially productive activities mainly depends on the experience of belonging, personal control and social recognition. We thus suggest that close social relationships and productive activities of good quality enhance well-being. Additionally, we hypothesise that the deficiency of close relationships and exclusion from productive activities induce poor well-being. ${ }^{15}$

\section{COHORT DESCRIPTION}

\section{Study design}

Pro-WELL is a longitudinal community-based study of persons with SCI and their partners. As we were interested in the long-term context of living with SCI, participants of the pro-WELL study were recruited as a sub-sample of a large community survey performed between 2011 and 2013, the Swiss Spinal Cord Injury Cohort Study (SwiSCI, see source population below). Given a main focus of the study on close social relationships and on socially productive activities such as caregiving, it was essential to include the partners of persons with SCI as well. Three measurement waves were accomplished over a period of 12 months (baseline; month 6; month 12). The baseline assessment was carried out between May 2015 and January 2016. A mixed mode design was used for data collection, consisting of standardised telephone interviews and questionnaires (paperpencil or online). Questionnaires contained the unique identification number, which together with a personal password worked as entry code for online completion.

We strictly observed all regulations concerning informed consent and data protection.

\section{Source population and recruitment procedure}

The first wave of the SwiSCI community survey (September 2011 to March 2013) served as a basis for the recruitment of pro-WELL participants (figure 1). ${ }^{31-33}$ The SwiSCI community survey included persons with traumatic or non-traumatic SCI aged over 16 years living in Switzerland. Persons with congenital conditions leading to SCI, new SCI in the context of palliative care, neurodegenerative disorders, cognitive impairment or Guillain-Barré syndrome were excluded. ${ }^{31}$ The SwiSGI population was recruited through the national association of persons with SCI (Swiss Paraplegic Association, SPA), three specialised SCI rehabilitation centres and an institution providing home care for persons with SCI. A total of 3144 persons were eligible for the SwiSCI survey and 1922 participated (response rate 61.1\%). ${ }^{32} 33$

Out of the 1922 SwiSCI participants serving as sampling frame, German- and French-speaking men and women aged 30-65 at time of the pro-WELL recruitment were contacted for eligibility screening $(n=1108$, figure 1). The lower end of this age range was chosen to preferentially include persons who completed their apprenticeship or secondary and tertiary education, while the upper end reflects retirement age in Switzerland. As 
Figure 1 Source population and participation status of eligible persons. SCl, spinal cord injury; SwiSCl, Swiss Spinal Cord Injury Cohort Study.

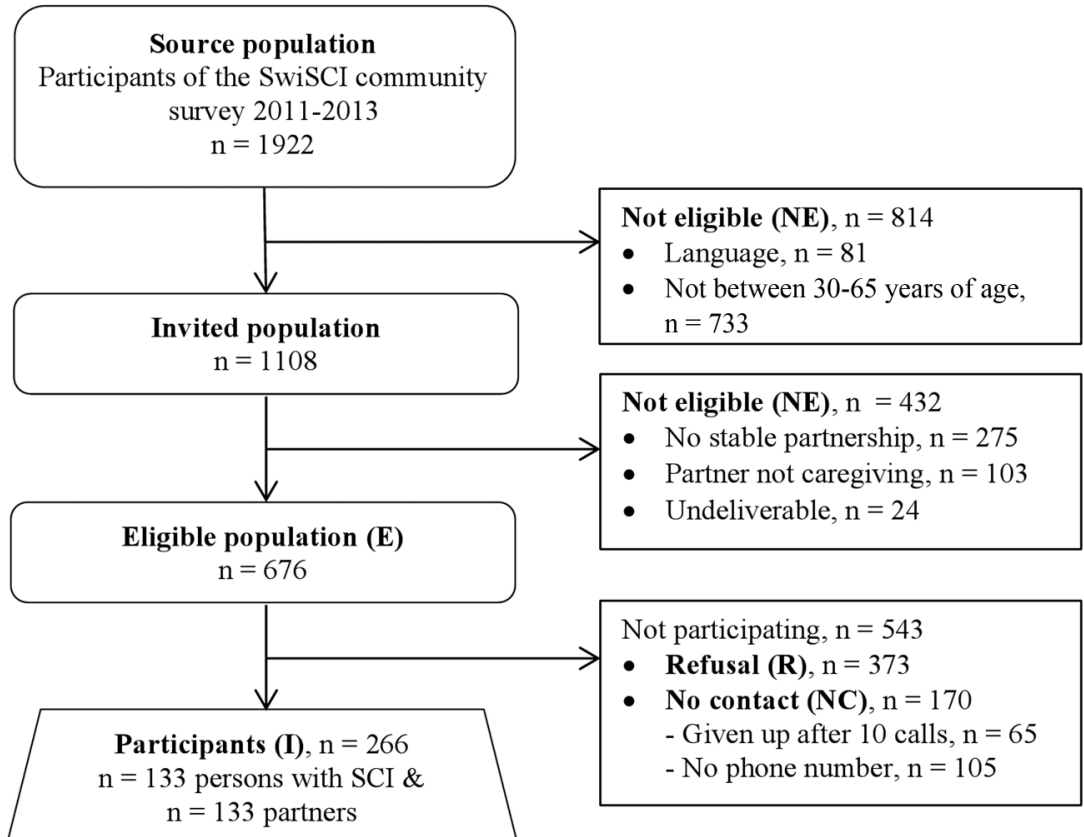

pro-WELL participants are recruited as a subsample of the SwiSCI community survey, the same inclusion and exclusion criterion mentioned in the paragraph before apply for the pro-WELL study. Given the study's focus on close social relationships, we included persons with SCI only if they were living in a stable relationship, if their partners were involved in any kind of caregiving tasks and agreed to participate as well. The assessment of whether a person was in a stable partnership or not was based on self-report of the person with SCI.

German- and French-speaking SwiSCI participants aged 30-65 were first contacted by postal mail including an invitational letter and a postpaid card to return to the SwiSCI study centre. The postcard contained an eligibility question (Do you live in a stable partnership at the moment?) and a general question on the agreement to be contacted by the study centre for further information on the pro-WELL study. Eligible persons who consented to be contacted for study participation and persons who did not respond to the written invitation were contacted by telephone 3 weeks after the initial mailing. If persons met eligibility criteria, the study was explained and study material including patient information and two copies of the consent form was sent. Within this recruitment call, participants could further define the mode and start of data collection (ie, arrangement of telephone interview date, sending of questionnaire or login data for online completion).

\section{Statistical power}

To evaluate the minimal sample size needed for an evaluation of the main hypothesis that involvement in a socially productive activity is positively associated with well-being, an a priori power analysis was conducted. Using the mean and variance in well-being of the source population, the minimal sample size to detect a half a SD difference in well-being was 132 pairs and to detect a $10 \%$ difference in well-being was 84 pairs, with $80 \%$ power ${ }^{34}$ and a significance level of $0.05 .^{34} 35$

\section{Measurements}

Socially productive activities: We collected basic information on the current employment situation of all participants (quantity of paid work; main occupational activity; number of employees in worksite) and additionally assessed workplace wheelchair accessibility, burden of disability in performing work, and fairness in persons with SCI. In employed persons, the quality of work was evaluated by established and psychometrically validated measures on autonomy (items from Job Content Questionnaire, JCQ), ${ }^{36}$ reciprocity (Effort-Reward Imbalance questionnaire, ${ }^{37}$ ERI short form ${ }^{38}$ ) and overcommitment. ${ }^{37}$ Criterion validity has been previously shown for the ERI short form and the items on autonomy from JCQ in an SCI population. ${ }^{39}$ New items on social support at work were designed based on JCQ. ${ }^{36}$ Further, incidence type, frequency and duration of voluntary engagement were assessed. To evaluate the quality of voluntary work, five items on reward (based on ERI) ${ }^{37}$ and two items on autonomy (based on JCQ) ${ }^{36}$ were newly developed to evaluate the quality of voluntary work. ${ }^{40}$ Amount of weekly hours of housework and days of childcare were assessed as quantity measures of housework. Four items on effort and three items on reward from the validated ERI scale for housework ${ }^{41}$ were selected to assess reciprocity in housework. Yet, those items were not used in disability research. Further, new items on autonomy (based on JCQ) ${ }^{36}$ and partner support in housework were measured as quality aspects. To assess quantity of caregiving, partners were requested 
to provide information on the daily hours of caregiving, the involvement of other persons or institutions in caring, and type of care provided. ${ }^{42}$ Caregiver burden was measured with the Zarit Burden Interview (ZBI) ${ }^{43}$ short form. ${ }^{44}$ The ZBI short form has recently been validated in an SCI population. ${ }^{45}$ New items were developed to assess reciprocity (based on ERI), ${ }^{37}$ autonomy and social support in caregiving.

Social relationships: Social networks were assessed by five items from the Social Network Index (SNI) ${ }^{46}{ }^{47}$ measuring participation in different types of social relationships, including relationships with friends and family, club membership and religious activities. A more thorough examination of club membership, as well as emotional and tangible aspects of social support were measured by items of the Swiss Health Survey (SHS) 2012. ${ }^{48}$ Tangible aspects include support in housework, health issues, financial issues, activities of daily living (in persons with SCI only) and caregiving (in partners only). Two new items were developed to assess virtual social network activity. Three items from the revised UCLA loneliness scale $^{49}$ were used to capture subjective feelings of loneliness. These items showed good internal consistency and satisfying convergent and divergent validity in SCI. ${ }^{50}$ Quality of partner relationship was assessed by the social support and depth subscales of the Quality of Relationship Inventory (QRI). ${ }^{51}{ }^{52}$ Reciprocity in partner relationship was examined using items from established population-based cohort studies. ${ }^{40}{ }^{53}$ It is the first time that these items are applied in a population with disability. As not available in the literature, items on autonomy in close social relationships in persons with SCI were newly developed.

Well-being: The Positive and Negative Affect Scale (PANAS) ${ }^{54}$ short form,${ }^{55}$ the Satisfaction with Life Scale (SWLS), ${ }^{56}$ and a five-item selection ${ }^{57}$ of the World Health Organization Quality of Life-BREF instrument (WHOQoL-BREF) ${ }^{58}$ These well-being measures showed satisfying validity and reliability in SCI populations. ${ }^{57} 59$ Five new items based on the flourishing concept of Huppert $e t a l^{60}$ were used to assess subjective well-being.

Socioeconomic and sociodemographic characteristics: Level of education, net equivalence household income, perceived financial hardship, house ownership (yes/no) and subjective social status were chosen as indicators of individual-level socioeconomic circumstances. Education was classified according to the International Standard Classification of Education as total years of formal education, combining school and vocational training. ${ }^{61}$ Income was measured by net equivalent household income in Swiss Francs, including information on disposable income, weighted by number of adults and children according to Organisation for Economic Co-operation and Development (OECD) criteria. ${ }^{62}$ Financial hardship was assessed by a single item on how participants get along with the available financial resources. The MacArthur Scale of subjective social status ${ }^{63}$ was used to capture the subjective evaluation of the place on a 'social ladder' asking participants to cross the rung on which they would place themselves in a hierarchically structured society represented by a 10-rung ladder. Basic sociodemographic characteristics include age, sex, household composition, marital status, marital year, beginning of partnership, number and age of children, nationality, and year of immigration in case of non-Swiss nationality.

Lesion characteristics and health problems: Data on lesion characteristics (paraplegia, tetraplegia; complete lesion, incomplete lesion; time since injury; aetiology) of persons with SCI were available from the SwiSCI community survey. Information on health problems include 10 items on frequent comorbidities from the Survey of Health, Ageing and Retirement in Europe (SHARE) ${ }^{64}$ and the 36-item Short Form Health Survey (SF-36) V.2 subscales general health, role limitations due to physical health, role limitations due to mental health, energy and fatigue, mental health, and pain. ${ }^{65}$ The SF-36 has shown satisfactory instrument validity and is widely used in SCI research. ${ }^{66}{ }^{67}$ For persons with SCI, common SCI-specific health problems were assessed using 10 items of the Spinal Cord Injury Secondary Conditions Scale (SCI-SCS). ${ }^{68}$

Personal factors and health behaviour: A five-item selection $^{69}$ of the General Self-Efficacy (GSES) Scale, ${ }^{70}$ the Rosenberg Self-Esteem Scale (RSES) ${ }^{71}$ short form, ${ }^{72}$ the Purpose in Life scale (PIL) ${ }^{73}$ short form ${ }^{74}$ and a single item on negative major life events during the past 6 months were used to capture personal factors. The short form measures of GSES, ${ }^{69}$ RSES $^{9}$ and PIL $^{59}$ showed satisfying psychometric properties in SCI populations. Information on current smoking status, amount and years of smoking, ${ }^{75}$ amount and frequency of fruit, vegetable $^{48}$ and alcohol intake, ${ }^{76}$ and physical activity was gathered to assess health behaviour.

Most of these constructs were psychometrically tested in general populations as well as in persons with SCI (see references above). New tools were developed for other core constructs including specific quality aspects of socially productive activities and close social relationships (ie, personal control, social recognition and belonging) because appropriate tools could not be retrieved from the literature. The psychometric evaluation of these instruments is planned following completion of the pro-WELL data collection.

\section{Statistical analysis}

Description of participation rates: We use the overall term participation rate to describe different types of rate calculations related to recruitment outcomes including contact, cooperation and response rate. ${ }^{77}$ According to internationally established guidelines, ${ }^{77}$ we display the cooperation, contact and response rates of the pro-WELL baseline assessment.

Description of participants' characteristics: Basic characteristics of pro-WELL participants (separately for persons with SCI and partners) and eligible samples from the SwiSCI source population are described. Basic 
characteristics included sex, age at time of data collection, years of education, net equivalence household income, paid employment (employed vs not employed), language (German vs French), membership in SPA (member vs non-member), lesion characteristics (complete paraplegia, incomplete paraplegia, complete tetraplegia, incomplete tetraplegia), aetiology (traumatic vs non-traumatic), years since injury and well-being (binary derived from WHOQoL-BREF; less than good vs good or very good). Participants of the SwiSCI community survey $^{32} 33$ who fulfilled the eligibility criteria (source population) were compared with the subgroup of pro-WELL participants in terms of basic characteristics and well-being. To evaluate differences, $p$ values from $\chi^{2}$ tests for categorical and t-tests for continuous variables were derived. Data for this analysis was taken from the SwiSCI community survey as a direct comparison of the baseline characteristics of the pro-WELL study and the eligible population was not possible due to the time delay between the two data collection periods. A direct comparison would not take into account the time-varying variables such as age and time since injury, moreover it would be inhibited as we do not have any contemporary data on those eligible individuals who did not participate in the pro-WELL study.

Analysis of non-response: To assess potential non-response bias, we used multivariable logistic regression to evaluate the propensity of participation in the pro-WELL study for members of the source population. Predictor variables in the analysis included key sociodemographic and lesion characteristics as well as well-being. Unadjusted and adjusted ORs and their 95\% CIs for participation in pro-WELL are presented. Missing data from the source population were accounted for using multiple imputation and all analyses were carried out using the appropriate methods for imputed data. A multiple variable approach was applied for the response, testing the significance of each predictor globally using Equal Fraction-Missing-Information (FMI) tests. In case of test significance for parameters with more than two levels, meaningful differences across levels were evaluated using pairwise comparisons with Bonferroni adjustments to account for multiple testing. Propensity scores and inverse probability weights (IPWs) were calculated for the pro-WELL sample. IPWs serve as sampling weights to account for unit non-response and can be used for sensitivity analysis in future pro-WELL data analyses.

Statistical analyses were performed using Stata V.13.1 (Statacorp).

\section{FINDINGS TO DATE}

\section{Source population, participation status and participation} rates of the baseline assessment

In total, 1108 persons were invited for the pro-WELL study and 676 persons were identified as eligible. Of the 432 not meeting the inclusion criteria, 275 were not in a stable partnership, 103 had a partner who did not carry out any caregiving tasks, and 24 invitations were undeliverable. In total, 373 eligible persons refused participation (refusal either by person with SCI or partner, or both), and 170 persons could not be contacted due to absence of telephone contact details. Finally, 133 persons with SCI and their partners (total $n=266$ ) completed the baseline assessment of the pro-WELL study (figure 1 and table 1). Around 26\% of contacted persons participated in the study (cooperation rate). Nearly $85 \%$ of invited persons could be contacted (contact rate), indicating that telephone contact could not be established in $15 \%$ of invited persons as there was no valid telephone number or we gave up calling after 10 attempts. Around $20 \%$ of eligible persons participated in the study (response rate), accounting for 133 persons with SCI and their partners (table 1).

\section{Basic characteristics of pro-WELL baseline participants}

Table 2 provides an overview of basic characteristics and well-being of study participants at baseline. Around three-quarters of participants with SCI were men, and three-quarters of partners were women. Almost $70 \%$ of all couples were German-speaking. Mean age in partners was slightly lower than in persons with SCI (49.7 vs 51.5 years), while years of education were almost equal between persons with SCI and partners (13.9 vs 14.0 years). In total, $57.1 \%$ of participants with SCI and $66.9 \%$ of partners were in paid employment. Persons with SCI reported a mean net equivalence household income of SFr4585 per month, while partners reported a somewhat lower income (SFr4376). Conversely, partners rated their well-being higher than persons with SCI (good or very good: $71.3 \%$ partners vs $48.5 \%$ persons with SCI).

Table 1 Eligibility, participation status and participation rates for the pro-WELL baseline assessment

\begin{tabular}{|c|c|c|}
\hline & $\begin{array}{l}\text { Abbreviations/ } \\
\text { formula* }^{*}\end{array}$ & $\begin{array}{l}\text { Pro-WELL } \\
\text { baseline } \\
\text { assessment } \\
\text { (persons with } \\
\text { SCI) }\end{array}$ \\
\hline Total invited & $\mathrm{I}+\mathrm{R}+\mathrm{NC}+\mathrm{NE}$ & 1108 \\
\hline Eligible total & $\mathrm{I}+\mathrm{R}+\mathrm{NC}=\mathrm{E}$ & 676 \\
\hline Not eligible & NE & 432 \\
\hline Participation & 1 & 133 \\
\hline Refusal & $\mathrm{R}$ & 373 \\
\hline No contact & $\mathrm{NC}$ & 170 \\
\hline \multicolumn{3}{|l|}{ Participation rates (\%) } \\
\hline Cooperation rate & {$[\mathrm{I} /(\mathrm{I}+\mathrm{R})] \times 100$} & $26.3 \%$ \\
\hline Contact rate & $\begin{array}{l}{[(\mathrm{I}+\mathrm{R}+\mathrm{NE}) /(\mathrm{I}+\mathrm{R}} \\
+\mathrm{NC}+\mathrm{NE})] \times 100\end{array}$ & $84.7 \%$ \\
\hline Response rate & {$[\mathrm{I} /(\mathrm{I}+\mathrm{R}+\mathrm{NC})] \times 100$} & $19.7 \%$ \\
\hline \multicolumn{3}{|c|}{$\begin{array}{l}{ }^{*} \text { Calculation of participation rates according to the definition of the } \\
\text { AAPOR. }{ }^{76} \\
\text { AAPOR, American Association of Public Opinion Research; E, } \\
\text { total eligible; I, participation; NC, no contact; NE, not eligible; R, } \\
\text { refusal; SCI, spinal cord injury. }\end{array}$} \\
\hline
\end{tabular}


Table 2 Basic characteristics of pro-WELL baseline participants and the eligible source population

\begin{tabular}{|c|c|c|c|c|c|}
\hline & $\begin{array}{l}\text { (1) SwiSCI 2011-2013, } \\
\text { data for pro-WELL } \\
\text { participants }\end{array}$ & $\begin{array}{l}\text { (2) Eligible source } \\
\text { population }\end{array}$ & $\begin{array}{l}\text { Difference between (1) } \\
\text { and (2) }\end{array}$ & $\begin{array}{l}\text { Pro-WELL baseline: } \\
\text { participants with SCI }\end{array}$ & $\begin{array}{l}\text { Pro-WELL baseline: } \\
\text { participants, partners }\end{array}$ \\
\hline Data collection (project and period) & $\begin{array}{l}\text { SwiSCI community } \\
\text { survey 2011-2013 }\end{array}$ & $\begin{array}{l}\text { SwiSCI community } \\
\text { survey 2011-2013 }\end{array}$ & $\begin{array}{l}\text { SwiSCI community } \\
\text { survey } 2011-2013\end{array}$ & $\begin{array}{l}\text { Pro-WELL } \\
\text { 2015-2016 }\end{array}$ & $\begin{array}{l}\text { Pro-WELL } \\
\text { 2015-2016 }\end{array}$ \\
\hline Total & $133(100)$ & $676(100)$ & & $133(100)$ & $133(100)$ \\
\hline \multicolumn{6}{|l|}{$\begin{array}{l}\text { Categorical variables } \\
\text { (missing values in pro-WELL: } \\
\text { SCI; partner) }\end{array}$} \\
\hline \multicolumn{6}{|l|}{ Sociodemographic characteristics } \\
\hline Sex (0 missing values $\mathrm{SCl} ; 0$ partner) & & & 0.579 & & \\
\hline Male & $98(73.7,65.5$ to 80.5$)$ & $503(74.4,71.0$ to 77.6$)$ & -0.7 & $98(73.7,65.5$ to 80.5$)$ & $35(26.3,19.5$ to 34.5$)$ \\
\hline Female & $35(26.3,19.5$ to 34.5$)$ & $173(25.6,22.4$ to 29.0$)$ & 0.7 & $35(26.3,19.5$ to 34.5$)$ & $98(73.7,65.5$ to 80.5$)$ \\
\hline Paid employment $(0 ; 0)$ & $85(63.9,55.3$ to 75.7$)$ & $372(55.0,51.3$ to 58.8$)$ & 8.90 .006 & $76(57.1,48.5$ to 63.3$)$ & $89(66.9,58.4$ to 74.4$)$ \\
\hline Language of response & & & 0.634 & & \\
\hline German $(0 ; 0)$ & $93(69.9,61.5$ to 77.2$)$ & $482(71.8,68.3$ to 75.1$)$ & 1.90 .634 & $93(69.9,61.5$ to 77.2$)$ & $93(69.9,61.5$ to 77.2$)$ \\
\hline French & $40(30.1,22.8$ to 38.5$)$ & $189(28.2,24.9$ to 31.7$)$ & -1.9 & $40(30.1,22.8$ to 38.5$)$ & $40(30.1,22.8$ to 38.5$)$ \\
\hline $\begin{array}{l}\text { Swiss Paraplegic Association } \\
\text { membership (0) }\end{array}$ & $117(88.0,81.2$ to 92.5$)$ & $518(76.6,73.3$ to 79.7$)$ & $11.4<0.0001$ & $117(88.0,81.2$ to 92.5$)$ & - \\
\hline \multicolumn{6}{|l|}{ Lesion characteristics } \\
\hline Lesion severity (2) & & & 0.332 & & \\
\hline Complete paraplegia & $49(37.4,29.5$ to 46.1$)$ & $245(36.7,33.1$ to 40.5$)$ & 0.7 & $49(37.4,29.5$ to 46.1$)$ & - \\
\hline Incomplete paraplegia & $45(34.4,26.6$ to 43.0$)$ & $216(32.4,28.9$ to 36.0$)$ & 2.0 & $45(34.4,26.6$ to 43.0$)$ & - \\
\hline Complete tetraplegia & $13(9.9,5.8$ to 16.4$)$ & $86(12.9,10.5$ to 15.7$)$ & -3.0 & $13(9.9,5.8$ to 16.4$)$ & - \\
\hline Incomplete tetraplegia & $24(18.3,12.5$ to 26.0$)$ & $120(18.0,15.3$ to 21.1$)$ & 0.3 & $24(18.3,12.5$ to 26.0$)$ & - \\
\hline Aetiology (3) & & & 0.106 & & - \\
\hline Non-traumatic & $21(16.2,10.7$ to 23.6$)$ & $101(15.2,12.6$ to 18.1$)$ & 1.0 & $21(16.2,10.7$ to 23.6$)$ & - \\
\hline Traumatic & $109(83.8,76.4$ to 89.3$)$ & $565(84.8,81.9$ to 87.4$)$ & -1.0 & $109(83.8,76.4$ to 89.3$)$ & - \\
\hline Well-being $(3 ; 4)$ & & & 0.292 & & \\
\hline Good or very good & $60(50.4,41.5$ to 59.3$)$ & $256(48.1,43.9$ to 52.4$)$ & 2.3 & $63(48.5,39.9$ to 57.1$)$ & $92(71.3,62.9$ to 78.5$)$ \\
\hline Less than good & $61(49.6,40.7$ to 58.5$)$ & $276(51.9,47.6$ to 56.1$)$ & -2.3 & $67(51.5,42.9$ to 60.1$)$ & $37(28.7,21.5$ to 37.4$)$ \\
\hline Continuous variables & Mean (SD) & Mean (SD) & $\begin{array}{l}\text { Mean difference }(\mathrm{Cl}) \\
p \text { Value }\end{array}$ & Mean (SD) & Mean (SD) \\
\hline Age in years $(1 ; 6)^{*}$ & $47.9(9.3)$ & $46.7(9.8)$ & $1.13(-0.36$ to 2.60$) 0.14$ & $51.5(9.4)$ & $49.7(10.5)$ \\
\hline Years of education $(2 ; 7)$ & $14.2(3.2)$ & $13.7(3.5)$ & 0.5 (-0.41 to 1.03$) 0.07$ & $13.9(3.2)$ & $14.0(3.1)$ \\
\hline Household income $(19 ; 17)$ & $4362.7(1575.8)$ & $4178.4(1684.8)$ & $\begin{array}{l}184.32(-72.72 \text { to } \\
441.36) 0.16\end{array}$ & $4585.0(1493.2)$ & $4376.3(1567.9)$ \\
\hline Years since injury $(5)^{\star}$ & $17.6(11.4)$ & $16.5(11.5)$ & $1.06(-0.68$ to 2.80$) 0.23$ & $21.1(11.5)$ & - \\
\hline
\end{tabular}


A large majority of persons with SCI were SPA members $(88 \%)$. In total, $37.4 \%$ of the sample with SCI had incomplete paraplegia, $34.4 \%$ incomplete paraplegia, $18.3 \%$ incomplete tetraplegia and $9.9 \%$ complete tetraplegia. Traumatic SCI was the dominant cause of SCI $(83.8 \%)$ and on average, time since injury was 21.1 years, ranging from 4 to 54 years.

Comparison between pro-WELL baseline participants and the eligible source population

Table 2 further provides basic characteristics of the total of eligible persons $(n=676)$ in comparison to the
pro-WELL study population. A comparison between participants and eligible persons revealed differences of $\leq 3 \%$ for sex, employment rates, language region, lesion severity, aetiology and well-being. The largest difference between pro-WELL participants and the total of eligible persons was observed for SPA membership $(88.0 \%$ of pro-WELL participants vs $76.6 \%$ of the eligible population). Years of education were almost identical between the two groups, while household income was lower in the total of eligible persons. Age and time since injury were some 4.8 and 4.6 years lower in the eligible population; however, this difference is largely due to the time

Table 3 Unadjusted and adjusted ORs and its 95\% Cls for participation in the pro-WELL baseline assessment

\begin{tabular}{|c|c|c|c|c|}
\hline & \multicolumn{2}{|l|}{ Model 1} & \multicolumn{2}{|l|}{ Model 2} \\
\hline & OR (95\% Cl) & p Value & OR (95\% Cl) & p Value \\
\hline Sex & & 0.83 & & 0.65 \\
\hline Male & 1.00 & & 1.00 & \\
\hline Female & $1.05(0.68$ to 1.61$)$ & & $1.12(0.69$ to 1.80$)$ & \\
\hline Age in years & & 0.72 & & 0.72 \\
\hline $30-40$ & 1.00 & & 1.00 & \\
\hline $41-50$ & $1.00(0.59$ to 1.71$)$ & & $1.09(0.62$ to 1.94$)$ & \\
\hline $51-65$ & $1.18(0.71$ to 1.95$)$ & & $1.26(0.70$ to 2.27$)$ & \\
\hline Years of education (in quartiles) & & & & 0.61 \\
\hline Lowest ( 0 to 9 years) & 1.00 & 0.13 & 1.00 & \\
\hline Low to middle (>9 to 12 years) & $1.28(0.54$ to 3.04$)$ & & $0.88(0.35$ to 2.24$)$ & \\
\hline Middle to high (>12 to 16 years) & 1.87 (0.84 to 4.14$)$ & & 1.16 (0.48 to 2.78$)$ & \\
\hline Highest (>17 years) & $2.21(0.95$ to 5.13$)$ & & $1.36(0.54$ to 3.44$)$ & \\
\hline Household income (in quartiles) & & & & 0.07 \\
\hline Lowest (SFr0 to SFr2500) & 1.00 & 0.02 & 1.00 & \\
\hline Low to middle (SFr2501 to SFr3750) & 2.86 (1.38 to 5.92$)$ & & $2.69(1.26$ to 5.74$)$ & \\
\hline Middle to high (SFr3751 to SFr5250) & 2.30 (1.07 to 4.96$)$ & & $1.96(0.85$ to 4.51$)$ & \\
\hline Highest $(\mathrm{SFr}>5250)$ & 2.67 (1.28 to 5.58$)$ & & 2.18 (0.97 to 4.90$)$ & \\
\hline Paid employment & & 0.02 & & 0.07 \\
\hline No & 1.00 & & 1.00 & \\
\hline Yes & 1.58 (1.07 to 2.34$)$ & & 1.52 (0.96 to 2.39$)$ & \\
\hline Language of response & & 0.33 & & 0.07 \\
\hline German & 1.00 & & 1.00 & \\
\hline French & $1.23(0.81$ to 1.87$)$ & & 1.53 (0.96 to 2.44$)$ & \\
\hline Swiss Paraplegic Association membership & & $<0.001$ & & $<0.001$ \\
\hline No & 1.00 & & 1.00 & \\
\hline Yes & 2.59 (1.48 to 4.52$)$ & & 3.07 (1.66 to 5.67$)$ & \\
\hline Lesion severity & & 0.74 & & 0.24 \\
\hline Incomplete paraplegia & 1.00 & & 1.00 & \\
\hline Complete paraplegia & $0.97(0.62$ to 1.53$)$ & & $0.69(0.41$ to 1.15$)$ & \\
\hline Incomplete tetraplegia & 0.95 (0.55 to 1.66$)$ & & 0.93 (0.52 to 1.69$)$ & \\
\hline Complete tetraplegia & 0.69 (0.35 to 1.36$)$ & & $0.51(0.24$ to 1.07$)$ & \\
\hline Aetiology & & 0.79 & & 0.46 \\
\hline Non-traumatic & 1.00 & & 1.00 & \\
\hline Traumatic & $0.93(0.55$ to 1.57$)$ & & $0.80(0.44$ to 1.45$)$ & \\
\hline Years since injury & & 0.33 & & 0.73 \\
\hline $0-15$ & 1.00 & & 1.00 & \\
\hline $16-25$ & 0.31 (0.82 to 2.08$)$ & & $1.22(0.74$ to 2.03$)$ & \\
\hline$\geq 26$ & 1.36 (0.85 to 2.18$)$ & & $1.14(0.65$ to 1.98$)$ & \\
\hline Well-being & & 0.43 & & 0.91 \\
\hline Less than good & 1.00 & & 1.00 & \\
\hline Good or very good & $1.18(0.79$ to 1.75$)$ & & $0.98(0.63$ to 1.51$)$ & \\
\hline
\end{tabular}


interval of around 3 years between the two data collections.

\section{Analysis of non-response}

Table 3 displays results from multivariable logistic regressions by indicating unadjusted and adjusted ORs and their 95\% CI for pro-WELL participation. In unadjusted models, higher income, having paid employment and being member of SPA is associated with study participation. When including all covariates into the model, participation in pro-WELL remains related to SPA membership, with members being three times more likely to participate than non-members. All other basic characteristics were not associated with study participation in the fully adjusted model. As a sensitivity analysis, SPA membership was removed from the final model, while keeping all other covariates. This sensitivity analysis confirmed that no variable other than SPA membership was associated with pro-WELL participation. Median weight derived from propensity scores was 5.1 (SD 1.1; minimum 4.1, maximum 7.9), indicating that a participant of pro-WELL stands on average for 5.1 eligible persons in the community.

\section{STRENGTHS AND LIMITATIONS}

The pro-WELL study is among the first to integrate three crucial human needs (belonging, personal control and social recognition) into a coherent theoretical framework, to measure them in a systematic way and to test their explanatory power with regard to wellbeing. According to internationally established guidelines for reporting, ${ }^{77} 78$ recruitment outcomes and participation rates were described in detail. The effective sample size at baseline should also provide the study with sufficient statistical power for answering one of the key hypotheses that social productivity positively affects well-being. In addition, a comprehensive nonresponse analysis was performed, demonstrating that the sample provided a good representation of the source population. By providing IPWs, we have a sophisticated tool to perform sensitivity analysis at our disposal, assessing a potential influence of nonresponse on study findings. The inclusion of persons with SCI as well as their partners is a major innovative aspect of the pro-WELL study enabling an in-depth analysis of interpersonal dynamics in coping with disability. The longitudinal design of this study is considered a further strength, given the fact that a large majority of investigations on well-being in persons with SCI relied on cross-sectional data. ${ }^{79}$

Limitations include the following: first, given the observational nature of the study, causal inference is limited even within a prospective study design. Second, although the pro-WELL sample reflects the composition of the source population quite well, we cannot exclude potential (eg, socioeconomic) selection bias inherent to the source population and thus results of the pro-WELL study might not be generalisable for all persons with SCI and their partners. Third, by including persons with SCI only if their partner also agreed to participate, we may have excluded persons with SCI in low-quality relationships that are prone to low levels of well-being. Fourth, sampling bias may have been partly inherited from the source population, particularly the over-representation of SPA members who may represent a group of persons coping more actively with disability. However, previous analyses suggest that the inclusive sampling bias of the source population had minor impact on survey results that are particularly relevant to pro-WELL, including having a partner, education level, current paid employment and well-being. ${ }^{32}$ Fifth, the study received a relatively low response rate and the resulting small sample size might imply limited power to detect associations of well-being. Our study experienced similar difficulties in recruiting couples than did other studies located in Switzerland. ${ }^{80} 81$

Acknowledgements The authors are grateful to all the participants of the pro-WELL study for their time and effort spent in responding to our questions and to the research assistants Léonie Hayoz, Sabine Hiss, Anja Walker, Karin Steiner and Leslie Spengler for their great work in recruitment and data collection. This study has been financially supported by the Swiss National Science Foundation (SNF; grant number 100017_153256/1; to MWGB and $\mathrm{CF}$ ) and by the Swiss Paraplegic Foundation, Nottwil, Switzerland. The authors also acknowledge the support from the Steering Committee of the SwiSCI cohort study.

Collaborators Despite a relatively small sample size, this study offers options of scientific collaborations. The authors therefore invite researchers to contact the corresponding author for further arrangements.

Contributors CF and JS designed the study and wrote a first draft of this manuscript. HT and MWGB analysed the data and contributed to the interpretation of results. All authors worked on, reviewed and approved the final version of the manuscript.

Funding Swiss Paraplegic Foundation, Swiss National Science Foundation, grant number 100017_153256/1.

Competing interests None declared.

\section{Patient consent Obtained.}

Ethics approval The study protocol and all measurement instruments were approved by the Ethical Committee of Northwest and Central Switzerland (document EKNZ 2014-285).

Provenance and peer review Not commissioned; externally peer reviewed.

Data sharing statement No additional data are available.

Open Access This is an Open Access article distributed in accordance with the Creative Commons Attribution Non Commercial (CC BY-NC 4.0) license, which permits others to distribute, remix, adapt, build upon this work noncommercially, and license their derivative works on different terms, provided the original work is properly cited and the use is non-commercial. See: http:// creativecommons.org/licenses/by-nc/4.0/

\section{REFERENCES}

1. World Health Organization. World report on disability. Geneva: WHO, 2011.

2. Committee on Spinal Cord Injury. Spinal cord injury: progress, promise, and priorities. Washington DC: The National Academies Press, 2005.

3. Bickenbach J, Officer A, Shakespeare T, et al. International perspectives on spinal cord injury. Geneva: WHO, 2013. 
4. Lidal IB, Huynh TK, Biering-Sorensen F. Return to work following spinal cord injury: a review. Disabil Rehabil 2007;29:1341-75.

5. Craig A, Nicholson Perry K, Guest R, et al. Adjustment following chronic spinal cord injury: determining factors that contribute to social participation. Br J Health Psychol 2015;20:807-23.

6. van Leeuwen CM, Post MW, van Asbeck FW, et al. Social support and life satisfaction in spinal cord injury during and up to one year after inpatient rehabilitation. J Rehab Med 2010;42:265-71.

7. Migliorini C, Tonge B, Taleporos G. Spinal cord injury and mental health. Aust N Z J Psychiatry 2008:42:309-14.

8. Dijkers MP. Quality of life of individuals with spinal cord injury: a review of conceptualization, measurement, and research findings. J Rehabil Res Dev 2005;42(Suppl 1):87-110.

9. Coyle CP, Lesnik-Emas S, Kinney WB. Predicting life satisfaction among adults with spinal cord injuries. Rehabil Psychol 1994;39:95-112.

10. Muller R, Peter C, Cieza A, et al. The role of social support and social skills in people with spinal cord injury-a systematic review of the literature. Spinal Cord 2012;50:94-106.

11. Muller R, Peter C, Cieza A, et al. Social skills: a resource for more social support, lower depression levels, higher quality of life, and participation in individuals with spinal cord injury? Arch Phys Med Rehabil 2015;96:447-55.

12. Ottomanelli $L$, Lind $L$. Review of critical factors related to employment after spinal cord injury: implications for research and vocational services. J Spinal Cord Med 2009;32:503-31.

13. Kent ML, Dorstyn DS. Psychological variables associated with employment following spinal cord injury: a meta-analysis. Spinal Cord 2014:52:722-8.

14. Krause JS. The relationship between productivity and adjustment following spinal cord injury. Rehabil Couns Bull 1990;33:188-99.

15. Siegrist J, Fekete C. Fair opportunities, social productivity and wellbeing in disability: Towards a theoretical foundation. J Rehabil Med 2016:48:494-9.

16. Bowlby J. Attachment and loss. London: Hogarth Press, 1969.

17. Ryff CD, Singer B. The contour of positive human health. Psychol Inq 1998:9:1-28.

18. Bandura A. Social foundations of thought and action. Englewood, Cliffs, NJ: Prentice Hall, 1986

19. Mead GH. Mind, self, and society. Chicago: University of Chicago Press, 1934.

20. Pearlin LI. The sociological study of stress. J Health Soc Behav 1989;30:241-56

21. Gouldner AW. The norm of reciprocity: a preliminary statement. Am Sociol Rev 1960;25:161-78.

22. Berkman LF, Glass T. Social integration, social networks, social support, and health. In: Berkman LF, Kawachi I, eds. Social epidemiology. Oxford: Oxford University Press, 2000:137-73.

23. Merton RK. Social theory and social structure. New York: The Free Press, 1968.

24. Lindenberg S, Frey BS. Alternatives, frames and relative prices: a broader view of rational choice theory. Acta Sociol 1993;36:191-205.

25. Doyle L, Gough I. A theory of human need. Hong Kong: Macmillan, 1991.

26. Karasek R, Theorell T. Healthy Work. New York: Basic Books, 1990.

27. Siegrist J. Social reciprocity and health: new scientific evidence and policy implications. Psychoneuroendocrinology 2005;30: 1033-8.

28. United Nations Human Rights Office of the Higher Commissioner. Convention on the Rights of Persons with Disabilities. http://www. ohchr.org/EN/HRBodies/CRPD/Pages/ConventionRightsPersons WithDisabilities.aspx (accessed 21 Jul 2016)

29. Williams R, Murray A. Prevalence of depression after spinal cord injury: a meta-analysis. Arch Phys Med Rehabil 2015;96:133-40.

30. Post M, Noreau L. Quality of life after spinal cord injury. J Neurol Phys Ther 2005;29:139-46.

31. Post MW, Brinkhof MW, von Elm E, et al. Design of the Swiss Spinal Cord Injury Cohort Study. Am J Phys Med Rehabil 2011;90(Suppl 2):S5-16.

32. Brinkhof MW, Fekete $\mathrm{C}$, Chamberlain JD, et al. Swiss national community survey of functioning after spinal cord injury: protocol, characteristics of participants and determinants of non-response. J Rehab Med 2016:48:120-30.

33. Fekete C, Segerer W, Gemperli A, et al. Participation rates, response bias and response behaviours in the community survey of the Swiss Spinal Cord Injury Cohort Study (SwiSCI). BMC Med Res Methodol 2015;15:80

34. Cohen J. Statistical power analysis for the behavioral sciences. New York: Lawrence Erlbaum Associates, 1988.
35. Norman GR, Sloan JA, Wyrwich KW. Interpretation of changes in health-related quality of life: the remarkable universality of half a standard deviation. Med Care 2003;41:582-92.

36. Karasek R, Brisson C, Kawakami N, et al. The Job Content Questionnaire (JCQ): an instrument for internationally comparative assessments of psychosocial job characteristics. J Occup Health Psychol 1998;3:322-55

37. Siegrist J, Starke D, Chandola T, et al. The measurement of effort-reward imbalance at work: European comparisons. Soc Sci Med 2004;58:1483-99.

38. Leineweber $\mathrm{C}$, Wege $\mathrm{N}$, Westerlund $\mathrm{H}$, et al. How valid is a short measure of effort-reward imbalance at work? A replication study from Sweden. Occup Environ Med 2010;67:526-31.

39. Fekete C, Wahrendorf M, Reinhardt JD, et al. Work stress and quality of life in persons with disabilities from four European countries: the case of spinal cord injury. Qual Life Res 2014;23:1661-71.

40. Wahrendorf M, Ribet C, Zins M, et al. Perceived reciprocity in social exchange and health functioning in early old age: prospective findings from the GAZEL study. Aging Ment Health 2010;14:425-32.

41. Sperlich S, Peter R, Geyer S. Applying the effort-reward imbalance model to household and family work: a population-based study of German mothers. BMC Public Health 2012;12:12.

42. Schofield HL, Murphy B, Herrman HE, et al. Family caregiving: measurement of emotional well-being and various aspects of the caregiving role. Psychological Med 1997;27:647-57.

43. Zarit SH, Reever KE, Bach-Peterson J. Relatives of the impaired elderly: correlates of feelings of burden. Gerontologist 1980;20:649-55.

44. Bédard M, Molloy DW, Squire L, et al. The Zarit Burden Interview. A new short version and screening version. Gerontologist 2001;41:652-7.

45. Rajabi-Mashhadi MT, Mashhadinejad $\mathrm{H}$, Ebrahimzadeh $\mathrm{MH}$, et al. The Zarit Caregiver Burden Interview Short Form (ZBI-12) in spouses of veterans with chronic spinal cord injury, validity and reliability of the Persian version. Arch Bone Jt Surg 2015;3:56-63.

46. Berkman LF, Syme SL. Social networks, host resistance, and mortality: a nine-year follow-up study of Alameda County residents. Am J Epidemiol 1979;109:186-204.

47. Weyers S, Dragano N, Mobus S, et al. Low socio-economic position is associated with poor social networks and social support: results from the Heinz Nixdorf Recall Study. Int J Equity Health 2008;7:13.

48. Bundesamt für Statistik. Schweizerische Gesundheitsbefragung 2012. Telefonischer und schriftlicher Fragebogen. Neuchâtel: Bundesamt für Statistik, 2012.

49. Hughes ME, Waite LJ, Hawkley LC, et al. A short scale for measuring loneliness in large surveys: results from two population-based studies. Res Aging 2004;26:655-72.

50. Robinson-Whelen S, Taylor HB, Feltz M, et al. Loneliness among people with spinal cord injury: exploring the psychometric properties of the 3-item loneliness scale. Arch Phys Rehab Med 2016;97:1728-34.

51. Pierce GR, Sarason IG, Sarason BR. General and relationship-based perceptions of social support: are two constructs better than one? J Pers Soc Psychol 1991;61:1028-39.

52. Reiner I, Beutel M, Skaletz C, et al. Validating the German version of the Quality of Relationship Inventory: confirming the three-factor structure and report of psychometric properties. PLOS ONE 2012;7: e37380.

53. Chandola T, Marmot MG, Siegrist J. Failed reciprocity in close social relationships and health: findings from the Whitehall II study. $J$ Psychosom Res 2007;63:403-11.

54. Watson D, Clark LA, Tellegen A. Development and validation of brief measures of positive and negative affect: the PANAS scales. $J$ Pers Soc Psychol 1988;54:1063-70.

55. Thompson ER. Development and validation of an internationally reliable short-form of the positive and negative affect schedule (PANAS). J Cross Cult Psychol 2007;38:227-42.

56. Diener E, Emmons RA, Larsen RJ, et al. The satisfaction with life scale. J Pers Assess 1985;49:71-5.

57. Geyh S, Fellinghauer BA, Kirchberger I, et al. Cross-cultural validity of four quality of life scales in persons with spinal cord injury. Health Qual Life Outcomes 2010;8:94

58. World Health Organization. The World Health Organization Quality of Life (WHOQOL)-BREF. Geneva: WHO Press, 2004.

59. Peter C, Schulenberg SE, Buchanan EM, et al. Rasch analysis of measurement instruments capturing psychological personal factors in persons with spinal cord injury. J Rehab Med 2016;48:175-88.

60. Huppert FA, Marks N, Clark A, et al. Measuring well-being across Europe: description of the ESS well-being module and preliminary findings. Soc Indic Res 2009;91:301-15. 
61. UNESCO. International Standard Classification of Education (ISCED). Paris: UNESCO, 1997.

62. Hagenaars AK, de Vos K, Zaidi MA. Poverty statistics in the late 1980s: research based on micro-data. Luxembourg: Office for Official Publications of the European Communities, 1994.

63. Adler N, Stewart J. The MacArthur Scale of Subjective Social Status, 2007. http://www.macses.ucsf.edu/research/psychosocial/ subjective.php. (accessed 31 Jul 2016)

64. Borsch-Supan A, Brandt M, Hunkler C, et al. Data resource profile: the Survey of Health, Ageing and Retirement in Europe (SHARE). Int J Epidemiol 2013;42:992-1001.

65. Ware JE, Kosinski M, Dewey JE. How to score version two of the SF-36 health survey. Lincoln, RI: Quality Metric Incorporated, 2000.

66. Whitehurst DG, Engel L, Bryan S. Short Form health surveys and related variants in spinal cord injury research: a systematic review. J Spinal Cord Med 2014;37:128-38.

67. Forchheimer M, McAweeney M, Tate DG. Use of the SF-36 among persons with spinal cord injury. Am J Phys Med Rehabil 2004;83:390-5.

68. Kalpakjian CZ, Scelza WM, Forchheimer MB, et al. Preliminary reliability and validity of a Spinal Cord Injury Secondary Conditions Scale. J Spinal Cord Med 2007;30:131-9.

69. Peter C, Cieza A, Geyh S. Rasch analysis of the General Self-Efficacy Scale in spinal cord injury. $J$ Health Psychol 2014:19:544-55.

70. Schwarzer R, Jerusalem M. Skalen zur Erfassung von Lehrer- und Schülermerkmalen. Dokumentation der psychometrischen Verfahren im Rahmen der Wissenschaftlichen Begleitung des Modellversuchs Selbstwirksame Schulen. Berlin: Freie Universität Berlin, 1999.

71. Rosenberg M. Society and the adolescent self-image. Princeton, NJ: Princeton University Press, 1965.
72. Nezlek JB, Plesko RM. Day-to-day relationships among self-concept clarity, self-esteem, daily events, and mood. Pers Soc Psychol Bull 2001;27:201-11.

73. Chang RH, Dodder RA. The modified purpose in life scale: a cross-national validity study. Int J Aging Hum Dev 1983;18:207-17.

74. Schulenberg E, Schnetzer LW, Buchanan EM. The purpose in life test-short form: development and psychometric support. J Happiness Stud 2011;15:861-76.

75. Biering-Sorensen F, Krassioukov A, Alexander MS, et al. International spinal cord injury pulmonary function basic data set. Spinal Cord 2012;50:418-21.

76. Gmel G, Kuendig H, Maffli E, et al. Suchtmonitoring Schweiz/ Jahresbericht-Daten 2012. Bern: Bundesamt für Gesundheit, 2012.

77. American Association of Public Opinion Research. Standard definitions: Final dispositions of case codes and outcome rates for surveys, 2015. http://www.aapor.org/AAPOR_Main/media/ publications/Standard-Definitions2015_8theditionwithchanges April2015 logo.pdf (accessed 21 Jul 2016).

78. von Elm E, Altman DG, Egger M, et al. The Strengthening the Reporting of Observational Studies in Epidemiology (STROBE) statement: guidelines for reporting observational studies. PLoS Med 2007;4:e296.

79. Peter C, Muller R, Cieza A, et al. Psychological resources in spinal cord injury: a systematic literature review. Spinal Cord 2012;50:188-201.

80. Meier $\mathrm{C}$, Bodenmann $\mathrm{G}$, Moergeli $\mathrm{H}$, et al. Dyadic coping among couples with COPD: a pilot study. J Clin Psychol Med Settings 2012;19:243-54.

81. Braun M, Mura K, Peter-Wight M, et al. Toward a better understanding of psychological well-being in dementia caregivers: the link between marital communication and depression. Fam Process 2010;49:185-203. 